\title{
Determination of spatially varying Van der Burgh's coefficient from estuarine parameter to describe salt transport in an estuary
}

\author{
D. C. Shaha and Y.-K. Cho \\ School of Earth \& Environmental Sciences/Research Institute of Oceanography, Seoul National University, \\ Seoul, 151-742, Korea
}

Received: 25 October 2010 - Published in Hydrol. Earth Syst. Sci. Discuss.: 9 November 2010

Revised: 15 March 2011 - Accepted: 20 April 2011 - Published: 2 May 2011

\begin{abstract}
The estuarine parameter $v$ is widely accepted as describing the relative contribution of the tide-driven and density-driven mixing mechanism of salt transport in estuaries. Van der Burgh's coefficient $K$ is another parameter that also determines the relative strength of two mechanisms. However, a single value of $K$, which has been considered in previous studies, can not represent the spatial variation of these mechanisms in an estuary. In this study, the spatially varying $K$ has been determined from the $v$ value calculated using intensively observed longitudinal salinity transects of the Sumjin River Estuary with exponential shape. The spatially varying $K$ describes the spatial variation of these mechanisms reasonably well and is independent of the river discharge downstream of the estuary where the strong tides cause well mixed conditions. However, $K$ values increase upstream and are found to depend on the freshwater discharge, with suppressing vertical mixing. The $K$ value has been scaled on the basis of the $v$ value and ranges between 0 and 1 . If $K<0.3$, the up-estuary salt transport is entirely dominated by tide-driven mixing near the mouth. If $0.3<K<0.8$, both tide-driven and density-driven mixing contribute to transporting salt in the central regimes. If $K>0.8$, the salt transport is almost entirely by densitydriven circulation in the upper most regimes. In addition, another $K$-based dispersion equation has been solved by using this spatially varying $K$. The spatially varying $K$ demonstrates density-driven circulation more prominently at the location of strong salinity gradient compared with a single $K$ value.
\end{abstract}

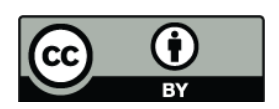

Correspondence to: Y.-K. Cho (choyk@snu.ac.kr)

\section{Introduction}

A general characteristic of estuaries is the presence of a horizontal density gradient, extending from the less dense riverine freshwater to the denser seawater. This horizontal density gradient is the key driving force for the estuarine circulation (Pritchard, 1952), characterizing by a seaward flow at the surface and a landward flow near the bottom. The dispersion should be proportional to the salinity gradient if the mixing is mostly density-driven (Savenije, 2006). In contrast, tide-driven dispersion is caused by tidal variations. Spring-neap variations in tidal shear stress may result in spring-neap variations in tidally driven mixing, stratification and gravitational circulation (Jay and Smith, 1990; Uncles and Stephens, 1996; Monismith et al., 1996; Ribeiro et al., 2004; Savenije, 2005). Nunes Vaz et al. (1989) suggested that the weaker turbulence during neap tide, when vertical mixing is suppressed, could lead to the acceleration of gravitational circulation (density-driven circulation). Such an influence of low mixing during neap tides was noted by Jay and Smith (1990) in the Columbia River Estuary, by Warner et al. (2005) in the Hudson River Estuary and by Shaha et al. (2010) in the Sumjin River Estuary.

On the basis of the estuarine parameter $v$, Hansen and Rattray $(1965,1966)$ discussed which of the two mechanisms (density-driven or tide-driven) is dominant to transporting salt in a certain estuary. $v$ is the proportion of the tide-driven dispersion to the total dispersion and has widely been used to describe the relative strength of salt transport mechanisms (Hansen and Rattray, 1966; Bowden and Gilligan, 1971; Officer and Kester, 1991; Dyer, 1997; MacCready, 2004; Savenije, 2005; Valle-Levinson, 2010). West and Broyd (1981) noted that tide-driven shear mechanism

Published by Copernicus Publications on behalf of the European Geosciences Union. 
dominated in narrow, shallow estuaries with a constant crosssection whereas density-driven shear mechanism dominated in wide estuaries with a funnel shaped (Smith, 1980). However, tide-driven and density-driven mixing varies along an estuary in accordance with the spring-neap tidal period and freshwater discharge. No single mechanism is solely dominated along an estuary. Tide-driven mixing is dominant mostly downstream of an estuary, a combination of the two mechanisms in the central regimes and gravitational mixing in the inner most regimes (McCarthy, 1993; Savenije, 2006; Shaha et al., 2010).

Van der Burgh's coefficient $K$ is another parameter used to describe the nature of salt transport mechanisms (both tidedriven and density-driven dispersion) in estuaries (Savenije, 2006). This coefficient determines the relative weight of these mechanisms. If $K$ is small, then tide-driven mixing is dominant in transporting salt. If $K$ approaches 1, gravitational circulation is dominant in transporting salt. Tidedriven dispersion dominates near the mouth of the Pungue and Maputo Estuaries (Savenije, 2005). In contrast, densitydriven mixing dominates upstream from the location of the strong salinity gradient. The value of $K$ obtained for both estuaries is 0.3 , which implies only the tide-driven dispersion mechanism transported salt in the Pungue and Maputo Estuaries. In reality, two mechanisms exist along the estuaries, indicating that no single value of $K$ can describe the nature of salt transport in estuaries, but it would vary along an estuary.

Savenije (2005) showed a solution to determine $K(=1 / v)$ from $v$ in an estuary with a constant cross-section, following the approach of Hansen and Rattray (1965). According to Hansen and Rattray's definition, Van der Burgh's coefficient is a proportion of the total effective dispersion to the tide-driven dispersion. However, the value of $K$ obtained from this solution $(K \geq 1)$ contradicts with the limits of $K(0<K<1)$, as Hansen and Rattray's relationship is derived under the assumption of a constant cross-sectional area along an estuary. However, Savenije (2005) suggested that $K$ would not be larger than unity in an estuary with an exponentially varying width, but no solution has been reported for determining $K$ from $v$ for such types of estuary where $K$ ranges between 0 and 1 .

The main focus of this study is to determine the spatially varying Van der Burgh's coefficient $K$ from the estuarine parameter $v$ in an estuary with an exponentially varying width. The estuarine parameter $v$ has been determined from longitudinal transects of salinity taken in the Sumjin River Estuary from 2004 to 2007. Thereafter, the values of $K$ are calculated with the assumption of an exponential function to the proportion of tide-driven dispersion to the total dispersion, i.e. $v$, following the approach of McCarthy (1993). $K$ ranges between 0 and 1 by representing both mechanisms of salt transport suggested by earlier researchers (Savenije, 1993, 2005; Eaton, 2007).

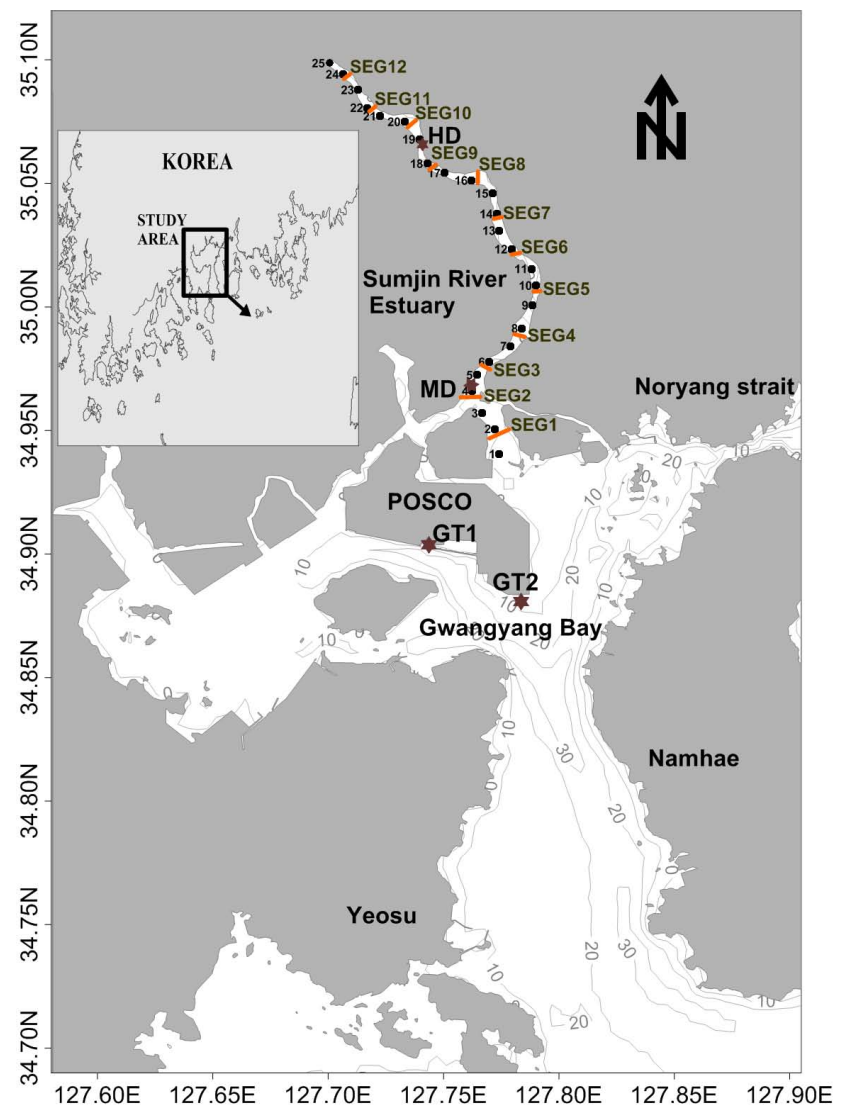

Fig. 1. Map of the study area. The solid circles indicate the CTD stations. The stars denote the locations of the Gwangyang (GT), Mangdock (MD) and Hadong (HD) tidal stations. The orange solid line indicates the locations (SEG1 $\sim 12$ ) of the boundary where the estuarine parameter $v$ and Van der Burgh's coefficient $K$ were calculated.

The rest of this paper is organized as follows. The study area and data sources are briefly presented in Sect. 2. The methods are described in Sect. 3. The results are presented in Sect. 4. A discussion follows in Sect. 5, with the conclusions summarized in Sect. 6.

\section{Study area and data}

The Sumjin River Estuary is one of the few natural estuaries on the south coast of Korea. This estuary enters Gwangyang Bay, connected in the south to the coastal sea (South Sea) and in the east to Jinjoo Bay through the narrow Noryang Channel (Fig. 1). Cross-sectional area $\left(\mathrm{m}^{2}\right)$, width (m) and depth (m) at cross-sections of all CTD stations of the Sumjin River Estuary are calculated by using SMS (Surface Water Modeling System) grid generation software (version 8.1), as shown in Fig. 2. The climate of Korea is characterized by four distinct seasons: spring (March, April and May), summer (June, July and August), autumn (September, 


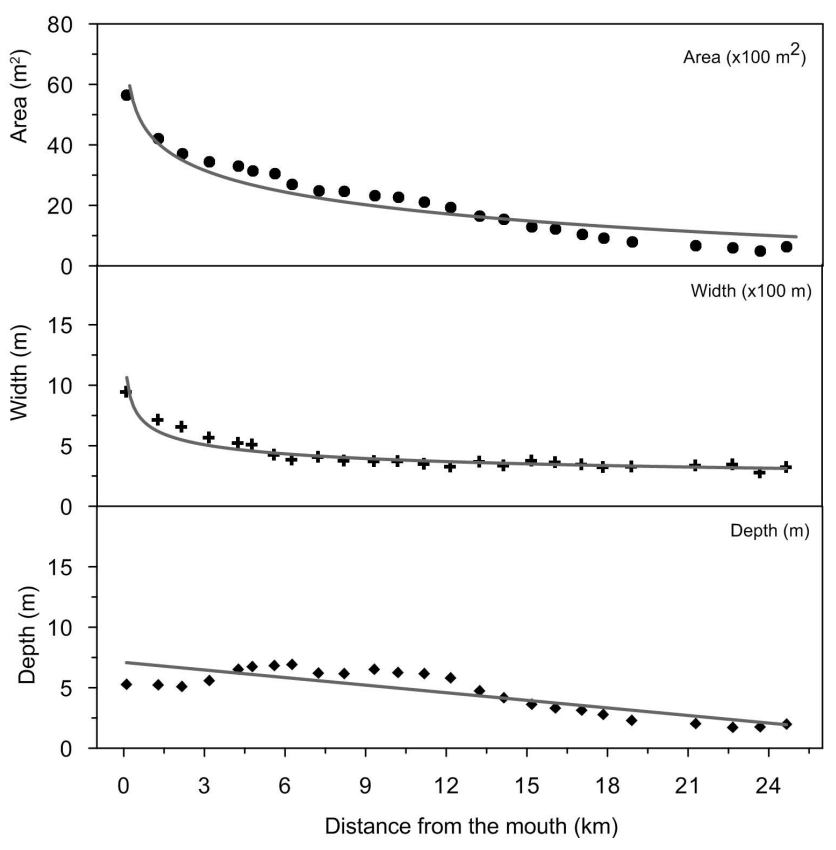

Fig. 2. Cross-sectional area (upper), width (middle) and depth (bottom) of all CTD stations of the Sumjin River Estuary.

October and November) and winter (December, January and February). Seasonal precipitation and runoff decrease during spring and winter, but increase during summer (Bae et al., 2008). The river discharge data used in this study were from the Songjung gauge station, located about $11 \mathrm{~km}$ upstream from CTD (conductivity-temperature-depth) station 24 operated by the Ministry of Construction and Transportation. The maximum monthly median river discharge appeared to be higher $\left(370 \mathrm{~m}^{3} \mathrm{~s}^{-1}\right)$ during July 2006 and lower $\left(11 \mathrm{~m}^{3} \mathrm{~s}^{-1}\right)$ during January 2005.

Tidal constituents for Gwangyang Bay (GT2, Fig. 1) were obtained from the Korean Ocean Research and Development Institute (http://www.kordi.re.kr/odmd/harmonic2004/). The $\mathrm{M}_{2}$ tide is the primary tidal constituent at the river mouth. Sea level data for 2005 and 2006 from the Hadong tidal (HD) gauge station (http://www.wamis.go.kr/wkw/WL DUBWLOBS.ASPX) were analyzed using the Task-2000 tidal package developed by the Proudman Oceanographic Laboratory (Bell et al., 1999). The tidal amplitudes of the $\mathbf{M}_{2}$ and $\mathrm{S}_{2}$ constituents are found to decrease with 12 and $8 \%$ within the estuary at HD, respectively (Shaha et al., 2010). The tidal cycle is semi-diurnal, with mean spring and neap ranges of 3.40 and $1.10 \mathrm{~m}$, respectively. The tidal information (high and low tides) was collected from the Gwangyang Tidal Station (GT1) operated by the National Oceanographic Research Institute, Korea, during the field observation period.

The longitudinal transects of salinity and temperatures were carried out at high water during both spring and neap tides in each season, from August 2004 to April 2007, using a CTD profiler (Ocean Seven 304 of IDRONAUT Company). A Global Positioning System was used to obtain the locations of the CTD stations (Fig. 1). The nominal distance between the CTD stations was $1 \mathrm{~km}$. Each cruise started from the estuary mouth about one and half hour before high or low waters and took approximately one and half hour to arrive at the last station when high or low waters slack occurred. The high water slack data surveyed from August 2004 to April 2007 were used in this study.

\section{Methods}

Van der Burgh (1972) developed an empirical method on the basis of the effective tidal average dispersion under equilibrium conditions. The longitudinal variation of the effective dispersion is given as follows:

$$
\frac{\partial[D(x)]}{\partial x}=K(x) \frac{Q}{A(x)}
$$

where $D(x)$ is the longitudinal dispersion coefficient, $Q$ is the river discharge, $A(x)$ is the tidal average cross-sectional area and $K(x)$ is the dimensionless Van der Burgh's coefficient. As $Q$ has a negative sign, the dispersion decreases upstream (Savenije, 2005). $K(x)$ determines the relative weights of the tide-driven and density-driven mixing mechanisms (Savenije, 2005). If $K$ is small, then tide-driven mixing is dominant to transport salt. If $K$ approaches 1, densitydriven mixing is dominant to transport salt.

Hansen and Rattray (1965) assumed that the salinity in the central zone of a narrow estuary with a constant crosssection would decrease linearly. The tide-driven dispersion $D_{\mathrm{t}}$ is then given as follows (Savenije, 2005):

$$
\frac{\partial D_{\mathrm{t}}(x)}{\partial x}=\frac{Q}{A(x)}
$$

In addition, Hansen and Rattray $(1965,1966)$ defined the estuarine parameter $v$ by the fraction of the salt advected seaward with the river discharge $(v S Q / A)$ that is balanced by the upstream salt flux associated with tidal dispersion $(D \partial S / \partial x)$. As a consequence, under steady state conservation of the mass equation for salt, $v$ equals the proportion of the tidedriven dispersion $D_{\mathrm{t}}(=D \partial S / \partial x)$ to the total dispersion $D$ $\left(=S U_{\mathrm{f}}=S Q / A\right)($ Savenije, 2005). $v$ can explicitly be given as a function of $x$.

$v(x)=\frac{D_{\mathrm{t}}(x)}{D(x)}=\frac{D(x) A(x)}{S Q} \frac{\partial S}{\partial x}$

If $v$ approaches 1 , the upstream transport of salt is entirely dominated by tide-driven processes. If $v$ is close to 0 , the up-estuary salt transport is almost entirely by gravitational circulation. If $0.1<v<0.9$, the system experiences a contribution of both gravitational circulation and tide-driven dispersion to the upstream transport of salt (Hansen and Rattray, 1966; Bowden and Gilligan, 1971; Officer and Kester, 1991; 
Dyer, 1997; Savenije, 2005; Valle-Levinson, 2010). Equation (3) was used to calculate the estuarine parameter $v$ in this study. A combination of Eqs. (2) and (3) is as follows:

$$
\frac{\partial[v(x) D(x)]}{\partial x}=\frac{Q}{A(x)}
$$

or

$$
\frac{\partial[D(x)]}{\partial x}=\left\{\frac{1}{v(x)}-\frac{D(x) A(x)}{v(x) Q} \frac{\partial[v(x)]}{\partial x}\right\} \frac{Q}{A(x)}
$$

The relation between the Van der Burgh's coefficient $K(x)$ and the estuarine parameter $v(x)$ for the case with spatially varying $v$ and $K$ can be written as follows from Eqs. (1) and (5).

$K(x)=\frac{1}{v(x)}\left\{1-\frac{D(x) A(x)}{Q} \frac{\partial[v(x)]}{\partial x}\right\}$

The longitudinal dispersion coefficient $D(x)$ is used to characterize the overall diluting capacity of an estuary. $D(x)$ can be calculated from integrated salt balance equation with respect to $x$ where the salinity of freshwater inflow is assumed as zero (Dyer, 1997: 79p.; Lewis and Uncles, 2003; Savenije, 2005: 154p.).

$D(x)=\frac{Q S(x) / A(x)}{\frac{\partial S}{\partial x}}$

Thus $D(x)$ can be calculated along the Sumjin River Estuary as $Q, A(x)$, and the longitudinal salinity distribution $S(x)$ are known. The numerator represents the advective rate of transport of salt towards the sea by the river flow, $Q$ per unit area of cross-section $A(x)$ and this is countered by the landward flux of salt due to non-advective processes. The denominator represents the longitudinal salinity gradient. Equation (7) is strictly inapplicable to stratified conditions (Dyer, 1997) and is a coefficient of effective longitudinal dispersion for well-mixed estuaries (Dyer, 1997; Savenije, 2005). On the basis of the stratification parameter $(\delta S /\langle S\rangle)$, which is the ratio of the top-to-bottom salinity difference $\delta S$ to the depth mean salinity $\langle S\rangle$, strongly stratified conditions were found in the Sumjin River Estuary during neap tide whereas wellto partially-mixed conditions during spring tide (Shaha and Cho, 2009). Therefore, this study will discuss only the spring tide condition throughout the paper.

The $K$ values calculated with Eq. (6) do not lie within the recommended ranges $(0<K<1)$ given by Savenije (1993, 2005) and Eaton (2007). $K$ values of Eq. (6) exceed the recommended range of 1 where $\partial S / \partial x, \partial v / \partial x$ and second term of Eq. (6) are $>2.0 \mathrm{~km}^{-1},>0.0666 \mathrm{~km}^{-1}$ and $<0.5$, respectively (Table 1$)$. The salinity curve exhibits an exponential decline, where the salinity decreases sharply and the $K$ values of Eq. (6) exceed the recommended limit in this location. In an exponential function, the function value is directly proportional to its gradient (Savenije, 2005). In addition, McCarthy (1993) showed how the dispersion decreases
Table 1. Different parameters of Eqs. (6) and (7) used to calculate the spatially varying $K$.

\begin{tabular}{rccccc}
\hline $\begin{array}{r}\text { Distance } \\
(\mathrm{km})\end{array}$ & $\begin{array}{c}\partial v / \partial x \\
\left(\mathrm{~km}^{-1}\right)\end{array}$ & $\begin{array}{r}\partial S / \partial x \\
\left(\mathrm{~km}^{-1}\right)\end{array}$ & $\begin{array}{c}\text { 2nd term } \\
\text { of Eq. }(6)\end{array}$ & $\begin{array}{r}K \text { from } \\
\text { Eq. }(6)\end{array}$ & $\begin{array}{r}K \text { from } \\
\text { Eq. }(8)\end{array}$ \\
\hline 0.54 & 0.0178 & 0.5767 & 0.980 & 0.052 & 0.058 \\
1.63 & 0.0103 & 0.3346 & 0.955 & 0.049 & 0.064 \\
2.71 & 0.0110 & 0.3559 & 0.940 & 0.046 & 0.079 \\
3.77 & 0.0190 & 0.6139 & 0.925 & 0.057 & 0.085 \\
4.80 & 0.0185 & 0.5980 & 0.896 & 0.073 & 0.108 \\
5.85 & 0.0297 & 0.9534 & 0.870 & 0.104 & 0.130 \\
6.90 & 0.0363 & 1.1706 & 0.839 & 0.136 & 0.159 \\
7.86 & 0.0293 & 0.9513 & 0.796 & 0.180 & 0.193 \\
8.76 & 0.0325 & 1.0526 & 0.761 & 0.247 & 0.228 \\
9.72 & 0.0426 & 1.3828 & 0.725 & 0.301 & 0.312 \\
10.72 & 0.0360 & 1.1683 & 0.677 & 0.371 & 0.330 \\
11.72 & 0.0389 & 1.2618 & 0.639 & 0.478 & 0.330 \\
12.68 & 0.0474 & 1.5414 & 0.599 & 0.573 & 0.371 \\
13.65 & 0.0426 & 1.3859 & 0.541 & 0.689 & 0.423 \\
14.61 & 0.0505 & 1.6347 & 0.493 & 0.929 & 0.471 \\
15.59 & 0.0666 & 2.1667 & 0.442 & 1.213 & 0.532 \\
16.62 & 0.0666 & 2.1668 & 0.374 & 1.579 & 0.615 \\
17.68 & 0.0669 & 2.1739 & 0.309 & 2.550 & 0.693 \\
18.77 & 0.0702 & 2.2862 & 0.252 & 5.232 & 0.759 \\
19.85 & 0.0758 & 2.4696 & 0.195 & 9.320 & 0.831 \\
20.88 & 0.0813 & 1.9576 & 0.131 & 19.340 & 0.915 \\
21.87 & 0.0804 & 1.7867 & 0.104 & 76.340 & 0.973 \\
22.87 & 0.0811 & 1.8300 & 0.063 & 86.749 & 0.987 \\
\hline
\end{tabular}

upstream and becomes zero near the toe of the salt intrusion curve in an estuary with an exponentially varying width. He used an exponential function, with a ratio of the dimensionless diffusion length scale to the tidal dissipation length scale. The dimensionless diffusion length scale is defined as the ratio of $K_{x} / R$, where $K_{x}$ is the longitudinal eddy diffusivities. $R$ is the ratio of the dimensional river flow to the scale for the nonlinear flow. $R$ cannot exceed order one (McCarthy, 1993).

In this study, an exponential function is also assumed with the proportion of tide-driven dispersion to the total dispersion $\left(D_{\mathrm{t}} / D\right)$, which limits the $K$ value to within one in an exponential shaped estuary, and describes the relative strength of tide-driven $(K \sim 0)$ and density-driven mixing $(K \sim 1)$ for the transport of salt. To satisfy the conditions for an exponential shaped estuary, the spatially varying $K$ is proposed in this study as follows:

$$
K(x)=\frac{1}{\exp (v(x))}\left\{1-\frac{D(x) A(x)}{Q} \frac{\partial[v(x)]}{\partial x}\right\}
$$

The assumption of an exponential function in Eq. (8), not only limits the range of $K(0<K<1)$ suggested by earlier researchers (Savenije, 2005; Eaton, 2007), but also describes the spatially varying tide-driven and density-driven mixing of salt transport in the Sumjin River Estuary (Table 1). The findings of the spatially varying salt transport mechanisms, 
on the basis of spatially different $K$ value, appears to be consistent with the observation of earlier researchers (McCarthy, 1993; Savenije, 1993, 2005; Eaton, 2007, Nguyen et al., 2008). However, a single value of $K$ can not describe these mechanisms.

\section{Results}

\subsection{Estuarine parameter $v$}

The estuarine parameter $v$, proposed by Hansen and Rattray $(1965,1966)$, has been widely accepted for describing the nature of salt transport in estuaries (Bowden and Gilligan, 1971; Fischer et al., 1979; Officer and Kester, 1991; Dyer, 1997; Savenije, 2005; Valle-Levinson, 2010; Shaha et al., 2010). This estuarine parameter $v$ obviously illustrates which exchange process is responsible for transporting salt up-estuary (Fig. 3). The tide-driven dispersion is almost entirely dominant landward from the mouth of the Sumjin River Estuary up to $6 \mathrm{~km}$ where $v>0.9$. This length is consistent with the median tidal excursion of the Sumjin River Estuary (Shaha and Cho, 2009). This length is extended up to $9 \mathrm{~km}$ landward from the estuary mouth with $v$ of $>0.8$ (Fig. 3), when the maximum tidal excursion of $9.4 \mathrm{~km}$ is considered (Shaha and Cho, 2009). This length is also consistent with the calculation of the widely accepted dimensionless stratification parameter, which describes the nature of salt transport in estuaries (Hansen and Rattray, 1966; Prandle, 1985; Dyer, 1997; Shaha and Cho, 2009; Valle-Levinson, 2010). On the basis of this stratification parameter, well-mixed conditions are found over this length (Shaha and Cho, 2009) due to the strong tidal effects during spring tide where the upstream transport of salt is entirely dominated by tide-driven mixing and gravitational circulation ceases.

Landward between 9 and $21 \mathrm{~km}$, both gravitational circulation and tide-driven dispersive fluxes contribute to transporting salt, where $v$ ranges between 0.1 and 0.8 . In these central regimes, the Sumjin River Estuary shows partially stratified conditions on the basis of the stratification parameter (Shaha and Cho, 2009) and also as a function of the potential energy anomaly on the water column (Shaha et al., 2010). The potential energy anomaly $(\phi)$ is the amount of work necessary to completely mix the water column $\left(\mathrm{J} \mathrm{m}^{-3}\right)$ which can be calculated from

$\phi=\frac{1}{H} \int_{-H}^{0} g z(\bar{\rho}-\rho) d z$

where $\rho$ is the vertical density profile over the water column of depth $H, z$ is the vertical coordinate and $g$ is the gravitational acceleration $\left(9.8 \mathrm{~ms}^{-2}\right)$. The amount of the potential energy in the water column increases over this length due to decreasing the tidal amplitude (Shaha et al., 2010). As

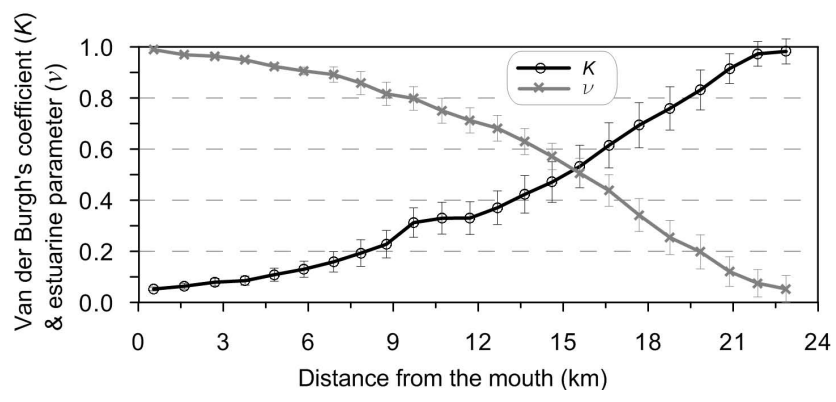

Fig. 3. Spatial variation of the median estuarine parameter $(v)$ and Van der Burgh's coefficient $(K)$ along the Sumjin River Estuary. If $v \sim 1$ and $K<0.3$, up-estuary transport of salt entirely by tide-driven mixing. If $v \sim 0$ and $K>0.8$, up-estuary salt transport almost entirely by gravitational circulation. If $0.1<v<0.8$ and $0.3<K<0.8$, both gravitational circulation and tide-driven circulation contribute to transporting salt up-estuary.

a consequence, the tidal exchange and gravitational circulation are both important for transporting salt upstream in this portion. Landward from $21 \mathrm{~km}$, the gravitational flux is almost entirely dominant in transporting salt upstream, where $v<0.1$. MacCready (2004) found $v \sim 0$ at the upstream end and $v \sim 0.8$ near the mouth of the Hudson River Estuary which is consistent with this study. Savenije (1993, 2005), MacCready (2004) and Nguyen et al. (2008) also found that gravitational circulation is solely important at the upstream end.

\subsection{Van der Burgh's coefficient $K$}

Van der Burgh's coefficient provides a solution for characterizing both salt flux mechanisms in the estuary described above. This coefficient has been calculated over the salt intrusion length of the Sumjin River Estuary using Eq. (8). Figure 3 depicts the spatial variation of Van der Burgh's coefficient $K$ along the Sumjin River Estuary. This dimensionless coefficient has been scaled on the basis of the widely accepted estuarine parameter $v$. Landward from the mouth of the estuary up to $9 \mathrm{~km}$, the transport of salt is entirely dominated by tide-driven mixing for the maximum tidal excursion of $9.4 \mathrm{~km}$ (Shaha and Cho, 2009; Table 2), where $v>0.8$ (Shaha et al., 2010). Under such a condition, $K$ is $<0.3$. Upstream from this location to $21 \mathrm{~km}$, both tidedriven and gravitational circulation contribute to transporting salt up-estuary, when $v$ ranges between 0.1 and 0.8 , and $K$ ranges between 0.3 and 0.8 . Gravitational circulation is almost entirely effective in transporting salt landward from $21 \mathrm{~km}$, where $v<0.1$ and $K>0.8$.

A comparison of the estuarine parameter with Van der Burgh's coefficient for characterizing the nature of the transport of salt in estuaries has summarized in Table 2. The $K$ value of 0.3 for the Maputo Estuary (Savenije, 2005), 0.25 for Flushing Bay (Eaton, 2007) and 0.3 for the Pungue 

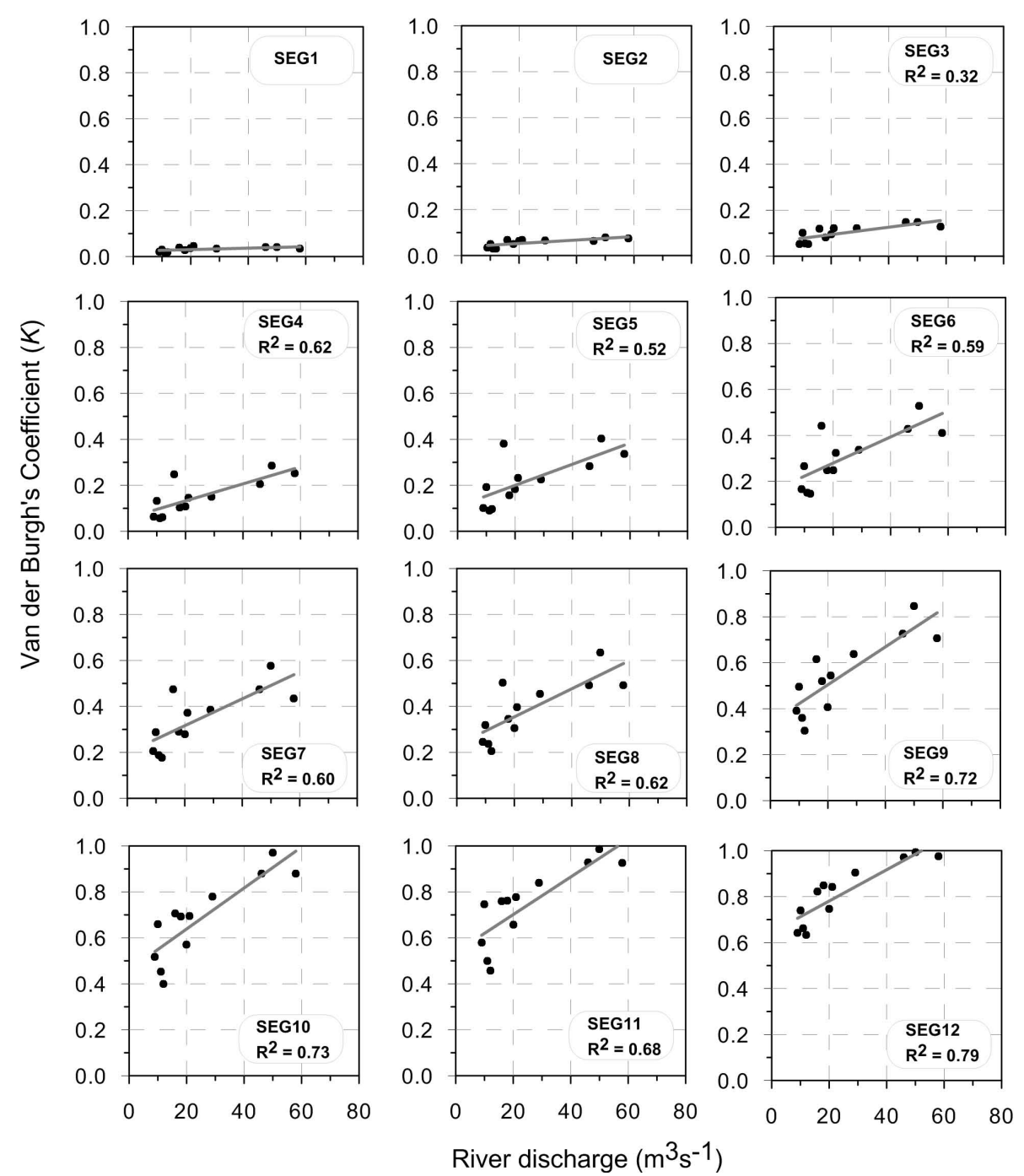

Fig. 4. Plots of the dimensionless Van der Burgh's coefficient $(K)$ against the river discharge for various segments of the Sumjin River Estuary.

Estuary (Savenije, 2005) imply that tide-driven mixing is the dominant mechanism. These values show well consistency with this scaling (Table 2). The $K$ value of 0.5 for the Limpopo Estuary (Savenije, 2005), 0.75 for the Chao Phya Estuary (Savenije, 2005) and 0.76 for the Sumjin River Estuary (Shaha and Cho, 2009) imply that density-driven mixing is much more effective than tide-driven mixing, which also shows well consistency.

To understand the effects of river discharge on the spatially varying $K, K$ values were plotted against the river discharge (Fig. 4). The $K$ values are almost constant for all river discharges near the mouth (SEG1 $\sim 3$ ). This indicates that tide-driven dispersive flux entirely dominates over gravitational circulation in transporting salt landward from the mouth up to $6 \mathrm{~km}$, as a result of the larger tidal amplitude of the spring cycle. On the basis of the estuarine parameter, tide-driven mixing is also dominant near the mouth during spring tide (Shaha et al., 2010). Upstream (SEG4 11), K depends on the freshwater discharges with a range of coefficient of determination $r^{2}$ between 0.52 and 0.73 . In contrast, a highly significant correlation is found between $K$ and the river discharges in segment 12 (SEG12). Savenije (2005) reported that $K$ is not a time-dependent factor. However, Fig. 4 clearly shows new findings of time-dependency of $K$. Thus, this study clearly reveals that $K$ is not only a spatially varying factor but also a time-dependency factor. Thereby, gravitational circulation and tide-driven dispersive flux differ with the rate of change in the salt content for various river discharges that can be described on the basis of the spatially varying $K$. 
Table 2. Values of the estuarine parameter and Van der Burgh's coefficient for characterizing the nature of salt transport in estuaries.

\begin{tabular}{lll}
\hline Estuarine parameter $v$ & Van der Burgh's coefficient & Nature of up-estuary salt transport \\
\hline$v \sim 0$ & $K>0.8$ & almost entirely by gravitational circulation \\
$v \sim 1$ & $K<0.3$ & almost entirely by tide-driven dispersion \\
$0.1<v<0.8$ & $0.3<K<0.8$ & a combination of both tide-driven dispersion and gravitational circulation \\
\hline
\end{tabular}

\section{Discussion}

Landward up to $60 \mathrm{~km}$ from the mouth of the Schelde Estuary, tidal mixing is the most important mechanism due to the ebb-flood channels interaction (Savenije, 1993). In contrast, density-driven mixing is dominant upstream from $60 \mathrm{~km}$ to $100 \mathrm{~km}$. The value of $K$ obtained in this estuary is 0.25 , which only depicts the tide-driven dispersive flux of salt. In reality, both tide-driven and density-driven mixing mechanisms exit in this estuary. Therefore, one would expect a higher value of $K$ for the inner regimes to describe the density-driven mixing mechanism. Likewise, tide-driven mixing is dominant in the wider part (downstream) of the Maputo Estuary, but density-driven mixing is dominant upstream (Savenije, 2005). The value of $K$ in this estuary is 0.3 , which also only demonstrates the tide-driven dispersion of salt. Therefore, the spatially varying $K$ is indeed required to describe the combined effect of tide-driven and densitydriven circulation in an estuary with an exponentially varying width.

Similarly, the $K$ value of the Sumjin River Estuary is 0.76 (Shaha and Cho, 2009), indicating that gravitational circulation is the dominant mechanism. However, on the basis of the stratification parameter (Shaha and Cho, 2009), the potential energy anomaly and the estuarine parameter (Shaha et al., 2010), tide-driven mixing mechanism is dominant landward up to approximately $9 \mathrm{~km}$ from the mouth of the Sumjin River Estuary. Thus, this single value could not describe the salt transport mechanism downstream. When the spatially different $K$ values are determined from Eq. (8), those values described the spatially varying salt transport mechanisms reasonably well. These findings are well consistent with the results of McCarthy (1993). He noted that tide-induced landward transport dominate near the mouth of an exponentially varying estuary, with density-driven mixing upstream. In this study, the same mechanisms of salt transport were found near the mouth with vigorous mixing due to the strong spring tidal currents. As a consequence, tide-driven mixing dominates near the mouth, but density-driven mixing dominates upstream. Therefore, it is clear that the spatially varying $K$ is necessary to more reasonably describe the nature of salt transport along the estuary. The value of $K$ given in Table 2 would assist in understanding the type of salt transport processes that exist along the estuary.
The spatially varying $K$ has also been used to solve the following $K$-based dispersion equation for describing the relative strengths of the tide-driven and density-driven mixing mechanisms. The dispersion is maximum near the estuary mouth, decreases in the upstream direction and becomes zero near the toe of the salt intrusion curve (Preddy, 1954; McCarthy, 1993; Savenije, 1993, 2005; Shaha et al., 2010). As gravitational circulation is proportional to the density gradient, the dispersion diminishes with the salinity gradient, until it becomes very small near the toe of the salt intrusion curve (Savenije, 2005). Equation (10) below was suggested by Savenije (1993) to describe the combination of densitydriven and tide-driven dispersion along the estuary.

$$
\frac{D}{D_{0}}=\left(\frac{S}{S_{0}}\right)^{K}
$$

where the subscript 0 refers to the situation at the mouth $(x=0), S$ the observed salinity along the estuary and $K$ the dimensionless Van der Burgh's coefficient, which ranges between 0 and 1 . When $K$ equals 1 , the curves of $D / D_{0}$ and $S / S_{0}$ coincide. Equation (10) has been applied to 16 different estuaries (Savenije, 1992) and bays (Eaton, 2007) to describe the relative strength of the tide-driven and densitydriven mixing mechanisms.

Equation (10) has been solved using both the spatially varying $K$ derived from Eqs. (6) and (8), and the single $K$ value of 0.76 (Shaha and Cho, 2009) for the Sumjin River Estuary. Figure 5 depicts how the normalized dimensionless dispersion curves perform in relation to the observed salt intrusion curves during winter with river discharge of $19 \mathrm{~m}^{3} \mathrm{~s}^{-1}$ and summer with river discharge of $50 \mathrm{~m}^{3} \mathrm{~s}^{-1}$ in the Sumjin River Estuary. The salinity gradient is negligible landward up to approximately $8 \mathrm{~km}$ from the estuary mouth as a result of the strong tidal effects during spring tide (Fig. 5a, red line). This indicates that tide-driven dispersion is almost constant and large over this length. This length is well consistent with the observed maximum tidal excursion during spring tide (Shaha and Cho, 2009). Signell and Butman (1992) noted that the tidal exchange zone extended roughly a tidal excursion from the mouth. Burchard and Hofmeister (2008) found that tide-driven exchange becomes dominant when the amount of the potential energy anomaly on the water column ranges between 0 and $10 \mathrm{~J} \mathrm{~m}^{-3}$, which is also consistent with this length (Shaha et al., 2010). 


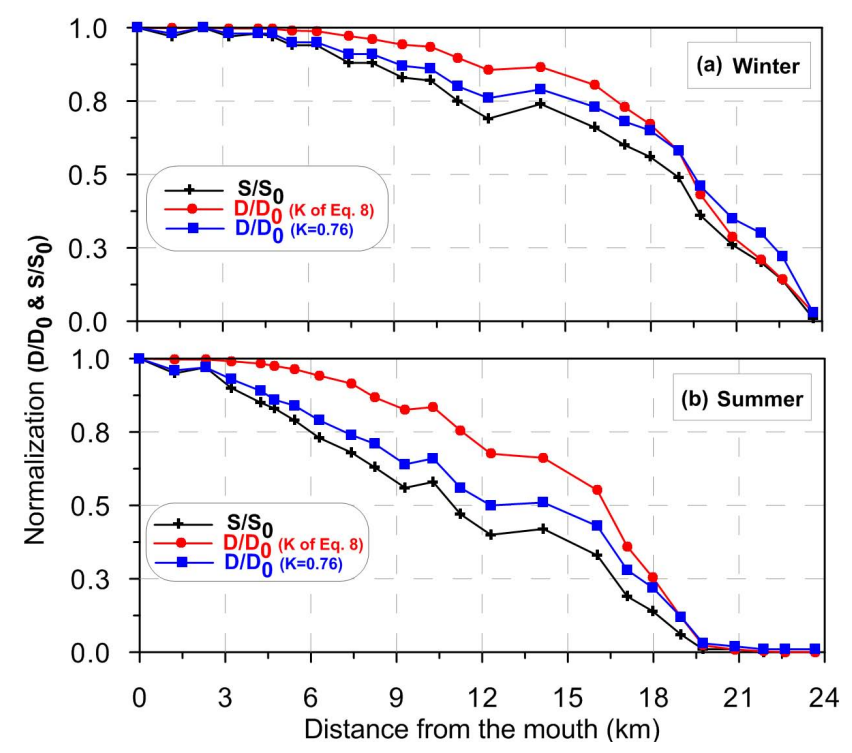

Fig. 5. Normalized dimensionless dispersion curves during (a) winter (discharge $19 \mathrm{~m}^{3} \mathrm{~s}^{-1}$ ) and (b) summer (discharge $50 \mathrm{~m}^{3} \mathrm{~s}^{-1}$ ) in the Sumjin River Estuary.

It can also been seen that density-driven dispersion is dominant in the middle regimes between approximately 9 and $21 \mathrm{~km}$ where the salinity gradient increases, and then drops to zero near the toe of the salt intrusion curve (Fig. 5a, red line). Comparing this dispersion curve with the curve of a single $K$ value (Fig. 5a, blue line), it is clear that the spatially varying $K$ value yields more pronounced density-driven circulation than a single $K$ value, where the salinity gradient is strong. Thus, the spatially varying $K$ shows well agreement with the theory (density-driven circulation becomes dominant where the salinity gradient is strong) compared to a single $K$ value. On the other hand, the spatially varying $K$ of Eq. (6) gives negative density-driven dispersion after approximately $15 \mathrm{~km}$ from the estuary mouth (not shown) where $K$ values exceed the recommended range of 1 . However, negative densitydriven dispersion has no physical meaning.

In contrast, when the river discharge increase in summer $\left(50 \mathrm{~m}^{3} \mathrm{~s}^{-1}\right)$, the tidal exchange is dominant landward up to approximately $5 \mathrm{~km}$ from the mouth and density-driven circulation becomes the dominant process between 6 and $19 \mathrm{~km}$ where the salinity gradient is strong (Fig. 5b, red line). In this case, the spatially varying $K$ also demonstrates density-driven circulation more prominently compared with a single $K$ value, where the salinity gradient is the steepest (Fig. 5b, blue line). This result is well consistent with result of McCarthy (1993), Savenije (1993, 2005), and Nguyen et al. (2008) that tide-driven mixing is dominant in the downstream part of estuaries, while density-driven mixing is dominant in the upstream part of estuaries.

Thus, this study will enhance the application of Eq. (10) by using the spatially varying $K$ determined from Eq. (8) to describe the relative strength of tide-driven and densitydriven mixing mechanisms of salt transport in an estuary with an exponentially varying width. This is because Eq. (8) describes the mixing processes well near the mouth, in the central regimes and near the toe of the salt intrusion curve in the Sumjin River Estuary.

\section{Conclusions}

Van der Burgh's coefficient $K$ can be used to describe the nature of the spatially varying salt transport mechanism in estuaries. $K$ is independent of the river discharge near the mouth under well-mixed conditions, where tide-driven mixing is dominant with $K<0.3$. However, $K$ depends on the river discharges in the central and inner regimes under partially mixed conditions, where both tide-driven and densitydriven mixing contribute to transporting salt up-estuary with $0.3<K<0.8$. Density-driven circulation is entirely dominant in the inner most regimes, with $K>0.8$.

The spatially varying Van der Burgh's coefficient $K$, determined from the estuarine parameter $v$ with the assumption of an exponential function, is physically appealing for the following reasons: (i) the spatially varying $K$ can describe the spatially different tide-driven and density-driven mixing contributions along the estuary compared with a single $K$ value. This describes the mixing processes reasonably well near the mouth, in the central regimes and near the toe of the salt intrusion curve in the Sumjin River Estuary, which corresponds with the observations of earlier studies, and (ii) the spatially varying $K$ also supports another $K$-based dispersion equation, which has been applied to 16 different estuaries and bays to describe the relative strength of the tidedriven and density-driven mixing mechanisms. Particularly, the spatially varying $K$ demonstrates density-driven circulation conspicuously at the strong salinity gradient location compared with a single $K$ value, which corresponds reasonably well with the theory. Thus, the spatially varying $K$ would enhance the application of the $K$-based dispersion equation. However, future study is necessary to derive an exponential function mathematically.

Acknowledgements. This research has been supported by the NAP program of the Korea Ocean Research Development Institute, and the project titled "Dynamics and prediction of long-term ocean climate variability" funded by MLTM. The authors are grateful to H. H. G. Savenije and two anonymous reviewers for their valuable comments, which substantially improved the paper. The authors would like to thank the members of the Marine Environment Prediction Laboratory for their enthusiastic supports during the data collection.

Edited by: H. H. G. Savenije 


\section{References}

Bae, D. H., Jung, I. W., and Chang, H.: Long-term trend of precipitation and runoff in Korean river basins, Hydrol. Process., 22, 2644-2656, 2008.

Bell, C., Vassie, J. M., and Woodworth, P. L.: POL/PSMSL Tidal Analysis Software Kit 2000 (Task-2000), Permanent Service for Mean Sea Level, CCMS Proudman Oceanographic Laboratory, Bidston Observatory, Birkenhead, UK, 20 pp., 1999.

Bowden, K. F. and Gilligan, R. M.: Characteristic feature of estuarine circulation as represented in the Mersey estuary, Limnol. Oceanogr., 16, 490-502, 1971.

Burchard, H. and Hofmeister, R.: A dynamic equation for the potential energy anomaly for analysing mixing and stratification in estuaries and coastal seas, Estuar. Coast. Shelf S., 77, 679-687, 2008.

Dyer, K. R.: Estuaries, A Physical Introduction, 2nd edition, John Wiley, London, UK, 195 pp., 1997.

Eaton, T. T.: Analytical estimates of hydraulic parameters for an urbanized estuary - Flushing Bay, J. Hydrol., 347, 188-196, 2007.

Fischer, H. B., List, E. J., Koh, R. C. Y., Imberger, J., and Brooks, N. H.: Mixing in Inland and Coastal Waters, 1st edition, Academic Press, New York, USA, 483 pp., 1979.

Hansen, D. V. and Rattray, R.: Gravitational circulation in straits and estuaries, J. Mar. Res., 23, 104-122, 1965.

Hansen, D. V. and Rattray, R.: New dimensions in estuary classification, Limnol. Oceanogr., 11, 319-326, 1966.

Jay, D. A. and Smith, J. D.: Circulation, density structure and neap-spring transitions in the Columbia River Estuary, Prog. Oceanogr., 25, 81-112, 1990.

Lewis, R. E. and Uncles, R. J.: Factors affecting longitudinal dispersion in estuaries of different scale, Ocean Dynam., 53, 197-207, 2003.

MacCready, P.: Toward a unified theory of tidally-averaged estuarine salinity structure, Estuaries, 27, 561-570, 2004.

McCarthy, R. K.: Residual currents in tidally dominated, wellmixed estuaries, Tellus A, 45, 325-340, 1993.

Monismith, S. G., Burau, S. R., and Stacey, M.: Stratification dynamics and gravitational circulation in northern San Francisco Bay, in: San Francisco Bay: The Ecosystem, edited by: Hollibaugh, J. T., American Association for the Advancement of Science, San Francisco, California, 123-153, 1996.

Nguyen, A. D., Savenije, H. H. G., van der Wegen, M., and Roelvink, D.: New analytical equation for dispersion in estuaries with a distinct ebb-flood channel system, Estuar. Coast. Shelf S., 79, 7-16, doi:10.1016/j.ecss.2008.03.002, 2008.

Nunes Vaz, R. A., Lennon, G. W., and de Silva Samarasinghe, J. R.: The negative role of turbulence in estuarine mass transport, Estuar. Coast. Shelf S., 28, 361-377, 1989.

Officer, C. B. and Kester, D. R.: On estimating the non-advective tidal exchanges and advective gravitational circulation exchanges in an estuary, Estuar. Coast. Shelf S., 32, 99-103, 1991.
Prandle, D.: On salinity regimes and the vertical structure of residual flows in narrow tidal estuaries, Estuar. Coast. Shelf S., 20, 615-635, 1985.

Preddy, W. S.: The mixing and movement of water in the estuary of the Thames, J. Mar. Biol. Assoc., 33, 645-662, 1954.

Pritchard, D. V.: A simple description and circulation in the Chesapeake Bay estuarine system, J. Mar. Res., 15, 33-42, 1952.

Ribeiro, C. H. A., Waniek, J. J., and Sharples, J.: Observations of the spring-neap modulation of the gravitational circulation in a partially mixed estuary, Ocean Dynam., 54, 299-306, 2004.

Savenije, H. H. G.: Rapid assessment technique for salt intrusion in alluvial estuaries, Ph.D Thesis, Delft University of Technology, 186 pp., 1992.

Savenije, H. H. G.: Composition and driving mechanisms of longitudinal tidal average salinity dispersion in estuaries, J. Hydrol., 144, 127-141, 1993.

Savenije, H. H. G.: Salinity and Tides in Alluvial Estuaries, 1st edition, Elsevier, Amsterdam, The Netherlands, 197 pp., 2005.

Savenije, H. H. G.: Comment on "A note on salt intrusion in funnelshaped estuaries: Application to the Incomati estuary, Mozambique" by Brockway et al. (2006), Estuar. Coast. Shelf S., 68, 703-706, 2006.

Shaha, D. C. and Cho, Y.-K.: Comparison of empirical models with intensively observed data for prediction of salt intrusion in the Sumjin River estuary, Korea, Hydrol. Earth Syst. Sci., 13, 923933, doi:10.5194/hess-13-923-2009, 2009.

Shaha, D. C., Cho, Y.-K., Seo, G.-H., Kim, C.-S., and Jung, K. T.: Using flushing rate to investigate spring-neap and spatial variations of gravitational circulation and tidal exchanges in an estuary, Hydrol. Earth Syst. Sci., 14, 1465-1476, doi:10.5194/hess14-1465-2010, 2010.

Signell, R. P. and Butman, B.: Modeling tidal exchange and dispersion in Boston Harbor, J. Geophys. Res., 97, 15591-15606, 1992.

Smith, R.: Buoyancy effects upon longitudinal dispersion in wide well-mixed estuaries, Philos. T. Roy. Soc. Lond., 296, 467-496, 1980.

Uncles, R. J. and Stephens, J. A.: Salt intrusion in the Tweed Estuary, Estuar. Coast. Shelf S., 43, 271-293, 1996.

Valle-Levinson, A.: Contemporary Issues in Estuarine Physics, 1st edition, Cambridge University Press, Cambridge, UK, 326 pp., 2010.

Van der Burgh, P.: Ontwikkeling van een methode voor het voorspellen van zoutverdelingen in estuaria, kanalen en zeeen, Rijkswaterstaat Rapport, 10-72, 1972.

Warner, J. C., Geyer, W. R., and Lerczak, J. A.: Numerical modeling of an estuary: A comprehensive skill assessment, J. Geophys. Res., 110, C05001, doi:10.1029/2004JC002691, 2005.

West, J. R. and Broyd, T. W.: Dispersion coefficients in estuaries, Proceedings of the Institution of Civil Engineers, 71, 721-737, 1981. 